\title{
Variatie in gebruik van JGZ-richtlijnen
}

\author{
Jacqueline A. Deurloo - Renate van Zoonen - Aniek A. E. M. van den Braak - Caren I. Lanting
}

Published online: 26 januari 2022

(C) Bohn Stafleu van Loghum is een imprint van Springer Media B.V., onderdeel van Springer Nature 2022

Samenvatting Inleiding. Sinds 1998 zijn er 35 Jeugdgezondheidszorg (JGZ)-richtlijnen ontwikkeld en gepubliceerd. Over het gebruik van richtlijnen door JGZprofessionals in de dagelijkse praktijk is geen recent onderzoek beschikbaar.

Methode: Via een digitale vragenlijst is onderzocht of de JGZ-richtlijnen gebruikt worden. Daarnaast is gekeken in hoeverre de twee belangrijkste kernaanbevelingen van een richtlijn in de praktijk worden toegepast ('gebruik zoals bedoeld'). Voor de richtlijnen die (bijna) nooit werden gebruikt, zijn de belemmerende factoren onderzocht.

Resultaten: De vragenlijst is ingevuld door 183 JGZprofessionals. Het gebruik van de JGZ-richtlijnen door JGZ-professionals varieert. De richtlijn Opsporen oogafwijkingen wordt door $85 \%$ van JGZprofessionals bijna altijd gebruikt, terwijl de richtlijn Begeleiden gezin bij overlijden kind door $18 \%$ bijna altijd wordt gebruikt. Het gebruik zoals bedoeld wisselt van $94 \%$ (Ondergewicht) tot $14 \%$ (Attention Deficit Hyperactivity Disorder, ADHD). De meest genoemde belemmeringen zijn: onvoldoende tijd, onvoldoende kennis en onvoldoende voordeel van de richtlijn.

Conclusie: Er bestaat een grote variatie in de mate waarin JGZ-richtlijnen worden gebruikt. Verbetering hierin is mogelijk voor het merendeel van de onderzochte richtlijnen. Aandacht voor de beschikbare tijd, kennis en voordeel voor professionals bij de ontwik-

\section{Dr. J. A. Deurloo $(\varangle) \cdot$ R. van Zoonen · Dr. C. I. Lanting TNO Child Health, Leiden, Nederland \\ jacqueline.deurloo@tno.nl}

Dr. J. A. Deurloo

GGD Hollands Noorden, Alkmaar, Nederland

A. A. E. M. van den Braak, Msc

Nederlands Centrum Jeugdgezondheid, Utrecht, Nederland keling, implementatie en borging van JGZ-richtlijnen is van belang voor een groter gebruik.

Trefwoorden richtlijnen - implementatie • jeugdgezondheidszorg

\section{Inleiding}

Wat heb je aan een richtlijn als hij niet wordt gebruikt? [1, 2]. Sinds 1998 zijn er 35 Jeugdgezondheidszorg (JGZ)-richtlijnen gepubliceerd. De JGZ-beroepsverenigingen (AJN Jeugdartsen Nederland, Verpleegkundigen \& Verzorgenden Nederland (V\&VN), Nederlandse Vereniging van DoktersAssistenten) zijn eigenaar van deze richtlijnen. Het Nederlands Centrum Jeugdgezondheid (NCJ) voert de regie over de JGZrichtlijnencyclus. Richtlijnen dragen bij aan een vermindering in variatie in handelen, en bevorderen het evidence-based handelen van professionals [3]. Einddoel is het verhogen van de opbrengst van (preventieve) zorg. Deze effecten zullen echter alleen optreden wanneer JGZ-professionals de JGZ-richtlijnen daadwerkelijk gebruiken.

Voor de huidige JGZ-praktijk is niet bekend in hoeverre professionals de JGZ-richtlijnen gebruiken. Een richtlijn kan nog zo goed zijn, als JGZ-professionals de richtlijn niet gebruiken, of niet gebruiken zoals bedoeld door de ontwikkelaars, dan heeft de richtlijn minder of geen effect. Uit een onderzoek naar het gebruik van negen JGZ-richtlijnen gepubliceerd voor 2012 bleek dat er een grote variatie was in de bekendheid met richtlijnen, de mate waarin richtlijnen werden gelezen en het (volledig) gebruik van richtlijnen [4]. Sindsdien is geen onderzoek gedaan naar het gebruik van JGZ-richtlijnen. Onlangs is wel een onderzoek verschenen naar de gecombineerde resultaten van praktijktests van JGZ-richtlijnen [5]. De sociale steun van leidinggevenden en ketenpartners en 
de beschikbare tijd voor JGZ-professionals bleken belangrijke belemmerende factoren bij de praktijktests van JGZ-richtlijnen.

Het is van belang dat richtlijnen gebaseerd zijn op actuele wetenschappelijke en praktijkkennis. Om flexibeler onderhoud van richtlijnen mogelijk te maken worden momenteel voorbereidingen getroffen om JGZ-richtlijnen modulair vorm te geven [6, 7]. Hierbij wordt een richtlijn opgedeeld in kleinere blokken, zogenaamde modules, die elk ingaan op een uitgangsvraag of praktisch knelpunt. Modulair vormgegeven richtlijnen kunnen gedeeltelijk herzien of aangevuld worden wanneer hier aanleiding toe is. Ook is de samenhang tussen richtlijnen gemakkelijker in kaart te brengen, wat de vindbaarheid van relevante informatie zal vereenvoudigen $[2,8]$.

Om te kunnen onderzoeken of een dergelijke modulaire werkwijze ook een positief effect heeft op het gebruik van JGZ-richtlijnen is een nulmeting nodig. Dit onderzoek kan als zodanig worden beschouwd. Het doel is om het gebruik van de JGZ-richtlijnen te meten onder JGZ-professionals. Hiervoor is gebruikgemaakt van een voor dit onderzoek ontwikkelde vragenlijst. Daarnaast wordt onderzocht welke belemmeringen JGZ-professionals ervaren om richtlijnen te gebruiken.

\section{Methode}

\section{Vragenlijst}

Voor het onderzoek is een digitale vragenlijst ontwikkeld, bestaande uit drie delen.

1. Gebruik: voor 33 JGZ-richtlijnen is uitgevraagd hoe vaak men deze gebruikt. De JGZ-richtlijnen Houding en bewegen en Ouder-kindrelatie zijn niet opgenomen in het onderzoek, omdat deze kort voor en na de start van het onderzoek werden gepubliceerd. Als uitgangspunt voor 'gebruik' is genomen: het toepassen van de kennis uit de richtlijn en het hiernaar handelen in de praktijk. In de vragenlijst is dit als volgt verwoord: 'Onder gebruik wordt verstaan "Het werken volgens de richtlijn". Je hoeft de richtlijn er dus niet specifiek bij te pakken.' Het antwoord werd ingevuld op een vijfpuntsschaal, variërend van nooit tot altijd. Daarnaast bestond de optie 'niet van toepassing', bijvoorbeeld wanneer de richtlijn niet past bij de leeftijdsgroep waar men mee werkt of als deze geen aanbevelingen voor de betreffende discipline bevat.

2. Gebruik zoals bedoeld: om hier een indruk van te krijgen is bij richtlijnen die men (bijna) altijd gebruikt de toepassing van twee kernaanbevelingen per richtlijn nagevraagd. Om de vragenlijst overzichtelijk te houden, is gekozen voor de twee meest relevante kernaanbevelingen. Deze selectie is gebaseerd op de professionele inschatting van de auteurs. Een kernaanbeveling bij de richtlijn
Lengtegroei (2019) is bijvoorbeeld: 'Bij een mogelijk afwijkende groei wordt anamnese en lichamelijk onderzoek verricht.'

3. Belemmerende factoren: voor richtlijnen die men soms of (bijna) nooit gebruikt, is nagevraagd wat de drie belangrijkste belemmerende factoren waren. Hierbij is gebruikgemaakt van de bevorderende en belemmerende factoren uit het Meetinstrument voor determinanten van innovaties (MIDI) [9].

De vragenlijst is vooraf getest door een jeugdarts, jeugdverpleegkundige, onderzoeker en richtlijn-implementatiedeskundige.

In de loop van 2020 is de landelijke uitvoering van de JGZ, en daarmee het gebruik van JGZ-richtlijnen, beïnvloed door de COVID-19-pandemie. Aan de deelnemers aan het onderzoek is daarom specifiek gevraagd om de vragenlijst in te vullen op basis van hun gebruik vóór de COVID-19-uitbraak.

\section{Werving van de deelnemers}

JGZ-professionals zijn geworven door middel van een oproep in nieuwsberichten van het NCJ en via de implementatiefunctionarissen van JGZ-organisaties. Daarnaast zijn twee vragen over het gebruik van richtlijnen opgenomen in het JGZ-richtlijnenspel, met een verwijzing naar de vragenlijst voor het onderzoek. De beroepsverenigingen AJN en V\&VN hebben hun leden via een e-mail en/of nieuwsbericht opgeroepen om deel te nemen aan het onderzoek.

\section{Analyse}

In eerder onderzoek werd de compleetheid van het gebruik aangemerkt als 'goed' als $80 \%$ of meer van de professionals bij (bijna) alle kinderen helemaal volgens de richtlijn werkt, als 'redelijk' als 50 tot $80 \%$ dit doet en 'matig' als minder dan $50 \%$ van de medewerkers dit doet [4]. In dit onderzoek is dezelfde indeling aangehouden voor het gebruik zoals bedoeld.

De data zijn geanalyseerd met SPSS versie 25 (IBM Corp. Armonk, NY, USA), waarbij beschrijvende statistiek is gebruikt.

\section{Resultaten}

\section{Deelnemers}

De vragenlijst is ingevuld door 183 JGZ-professionals. Het betrof 72 jeugdartsen (van wie 10 in opleiding), 8 verpleegkundig specialisten (van wie 2 in opleiding), 100 jeugdverpleegkundigen (van wie 10 geschoold in lichamelijk onderzoek) en 2 doktersassistentes. Van 1 deelnemer was de functie onbekend.

JGZ-professionals waren voornamelijk werkzaam in de zorg voor jeugdigen van 0 tot 4 jaar $(153 / 183,84 \%)$ en/of 4 tot 12 jaar $(105 / 183,57 \%)$. Een kleiner deel 
van de JGZ-professionals was werkzaam in de zorg voor jeugdigen ouder dan 12 jaar $(55 / 183,30 \%)$.

De JGZ-professionals waren afkomstig uit heel Nederland. De meeste JGZ-professionals gaven aan werkzaam te zijn in de regio West (55/192, 29\%), gevolgd door de regio's Midden (49/192, 26\%), Zuid (46/192, $24 \%)$, Oost $(25 / 192,13 \%)$ en Noord $(25 / 192$, $13 \%)$.

Bij veel organisaties zijn er een of meer personen aangewezen voor het coördineren van de invoering van JGZ-richtlijnen. Van de JGZ-professionals gaf de meerderheid $(122 / 180,67 \%)$ aan dat er 1 of meer personen zijn aangewezen. De overige JGZ-professionals gaven aan dat dit niet het geval was $(16 / 180,9 \%)$ of dat zij het niet wisten $(42 / 180,23 \%)$.

\section{Gebruik van de richtlijnen}

Tabel 1 laat zien hoe vaak JGZ-professionals de verschillende JGZ-richtlijnen naar eigen zeggen gebruiken. De drie meest gebruikte JGZ-richtlijnen zijn: Opsporen oogafwijkingen, Voorkeurshouding en schedelvervorming, en Taalontwikkeling. Respectievelijk $85 \%, 80 \%$ en $73 \%$ van de JGZ-professionals geeft aan deze richtlijn (bijna) altijd te gebruiken. De drie minst gebruikte JGZ-richtlijnen zijn: Angst, Astma en Begeleiding gezin bij overlijden kind. Respectievelijk 19\%, $19 \%$ en $18 \%$ van de JGZ-professionals gebruikt deze richtlijn (bijna) altijd, tegenover $49 \%$, $48 \%$ en $58 \%$ die aangeeft de richtlijn (bijna) nooit te gebruiken.

Per discipline zijn er verschillen zichtbaar in de meest gebruikte richtlijnen. Jeugdartsen en verpleegkundig specialisten gebruiken het vaakst de richtlijnen Lengtegroei, Opsporen oogafwijkingen en Hartafwijkingen. Jeugdverpleegkundigen gebruiken het vaakst de richtlijnen Opsporen oogafwijkingen, Voeding en eetgedrag, en Zindelijkheid. Tabel 2 toont de tien meest gebruikte richtlijnen per discipline.

\section{Gebruik zoals bedoeld}

Tabel 1 toont tevens het percentage JGZ-professionals dat beide kernaanbeveling(en) toepast bij (bijna) alle kinderen. Van de richtlijnen Ondergewicht, Voedselovergevoeligheid, en Voorkeurshouding en schedelvervorming worden beide kernaanbevelingen het vaakst uitgevoerd. Tabel 2 bevat de uitvoering van beide kernaanbevelingen per discipline.

Het gebruik zoals bedoeld ligt voor 8 van de 33 richtlijnen boven de $80 \%$, en is dus goed te noemen. Voor 10 van de 33 richtlijnen was het gebruik zoals bedoeld redelijk, maar voor 15 van de 33 richtlijnen was dit matig.

\section{Belemmerende factoren}

Bij de richtlijnen die de JGZ-professional soms of (bijna) nooit gebruikt is nagevraagd wat de 3 belangrijkste belemmerende factoren waren. De volgende
Tabel 1 Het gebruik per JGZ-richtlijn en het gebruik zoals bedoeld. De richtlijnen zijn gesorteerd van het vaakst naar het minst vaak gebruikt

\begin{tabular}{|l|r|r|}
\hline Richtlijn & \multicolumn{1}{l}{$\begin{array}{l}\text { Gebruik: } \\
n / N(\%)\end{array}$} & $\begin{array}{l}\text { Gebruik zoals } \\
\text { bedoeld }\end{array}$ \\
\hline & $(B i j n a)$ altijd & $\begin{array}{l}\text { Toepassing } 2 \\
\text { kernaanbevelin- } \\
\text { gen (bijna) altijd }\end{array}$ \\
\hline Opsporen oogafwijkingen & $153 / 179(85 \%)$ & $107 / 153(70 \%)$ \\
\hline Voorkeurshouding en schedelvorming & $124 / 155(80 \%)$ & $109 / 123(89 \%)$ \\
\hline Taalontwikkeling & $125 / 172(73 \%)$ & $104 / 125(83 \%)$ \\
\hline Preventie wiegendood & $110 / 152(72 \%)$ & $69 / 108(64 \%)$ \\
\hline Lengtegroei & $130 / 182(71 \%)$ & $76 / 130(58 \%)$ \\
\hline Excessief huilen & $108 / 154(70 \%)$ & $42 / 108(39 \%)$ \\
\hline Borstvoeding & $104 / 153(68 \%)$ & $89 / 104(86 \%)$ \\
\hline Overgewicht & $120 / 180(67 \%)$ & $39 / 120(33 \%)$ \\
\hline Hartafwijkingen & $112 / 168(67 \%)$ & $40 / 112(36 \%)$ \\
\hline Voeding en eetgedrag & $117 / 178(66 \%)$ & $99 / 117(85 \%)$ \\
\hline Zindelijkheid van urine en feces & $115 / 178(65 \%)$ & $34 / 114(30 \%)$ \\
\hline Gezonde slaap en slaapproblemen bij & $112 / 178(63 \%)$ & $72 / 112(64 \%)$ \\
\hline kinderen & & \\
\hline Kindermishandeling & $112 / 182(62 \%)$ & $93 / 112(83 \%)$ \\
\hline Heupdysplasie & $93 / 149(62 \%)$ & $82 / 93(88 \%)$ \\
\hline Voedselovergevoeligheid & $106 / 173(61 \%)$ & $99 / 105(94 \%)$ \\
\hline Huidafwijkingen & $101 / 176(57 \%)$ & $57 / 101(56 \%)$ \\
\hline Niet scrotale testis (NST) & $82 / 152(54 \%)$ & $38 / 81(47 \%)$ \\
\hline Motorische ontwikkeling & $92 / 173(53 \%)$ & $35 / 92(38 \%)$ \\
\hline Vroegtijdige opsporing van gehoorver- & $86 / 162(53 \%)$ & $28 / 85(33 \%)$ \\
\hline lies bij kinderen en jongeren & & \\
\hline Ondergewicht & $87 / 179(49 \%)$ & $80 / 85(94 \%)$ \\
\hline Extremiteiten & $74 / 165(45 \%)$ & $53 / 73(73 \%)$ \\
\hline Vroeg en/of small gestational age (SGA) & $68 / 152(45 \%)$ & $12 / 68(18 \%)$ \\
\hline geboren kinderen & & \\
\hline Hyperbilirubinemie & $71 / 166(43 \%)$ & $30 / 70(43 \%)$ \\
\hline Opvoedondersteuning & $72 / 179(40 \%)$ & $39 / 72(54 \%)$ \\
\hline Autismespectrumstoornissen & $64 / 175(37 \%)$ & $23 / 63(37 \%)$ \\
\hline Psychosociale problemen & $60 / 173(35 \%)$ & $35 / 60(58 \%)$ \\
\hline Seksuele ontwikkeling & $57 / 175(33 \%)$ & $16 / 57(28 \%)$ \\
\hline ADHD & $45 / 164(27 \%)$ & $6 / 44(14 \%)$ \\
\hline Depressie & $39 / 151(26 \%)$ & $18 / 38(47 \%)$ \\
\hline & $31 / 148(21 \%)$ & $23 / 31(74 \%)$ \\
\hline Pesten & $31 / 162(19 \%)$ & $9 / 31(29 \%)$ \\
\hline
\end{tabular}

factoren werden het vaakst genoemd: 'onvoldoende tijd' (397 keer), 'onvoldoende kennis' (259 keer), 'de richtlijn biedt mij geen voordeel' (196 keer), 'ik vind de richtlijn niet tot mijn taak behoren' (175 keer) en 'de richtlijn sluit niet aan bij de bestaande werkwijze' (133 keer). Daarnaast is aan de JGZ-professionals gevraagd of zij nog opmerkingen hadden. Hier werden de volgende factoren benoemd:

1. Het onderwerp komt niet vaak aan de orde (29 keer). Bijvoorbeeld: 'Er is heel weinig casuïstiek waar ik deze richtlijn bij nodig heb.' 
Tabel 2 De tien JGZ-richtlijnen die die het meest worden gebruikt, en waarbij beide kernaanbevelingen het vaakst worden toegepast, uitgesplitst naar discipline (jeugdartsen plus verpleegkundig specialisten en jeugdverpleegkundigen)

\begin{tabular}{|c|c|c|c|c|}
\hline & \multicolumn{2}{|l|}{ Top 10 gebruik JGZ-richtlijnen } & \multicolumn{2}{|c|}{ Top 10 gebruik zoals bedoeld (beide kernaanbevelingen toegepast) } \\
\hline & $\begin{array}{l}\text { Jeugdartsen + verpleegkundig specia- } \\
\text { listen }\end{array}$ & Jeugdverpleegkundigen & $\begin{array}{l}\text { Jeugdartsen + verpleegkundig speci- } \\
\text { alisten }\end{array}$ & Jeugdverpleegkundigen \\
\hline 1. & Lengtegroei & Opsporen oogafwijkingen & Ondergewicht & Voedselovergevoeligheid \\
\hline 2. & Opsporen oogafwijkingen & Voeding en eetgedrag & Heupdysplasie & Borstvoeding \\
\hline 3. & Hartafwijkingen & Zindelijkheid van urine en feces & Voedselovergevoeligheid & Voeding en eetgedrag \\
\hline 4. & Heupdysplasie & $\begin{array}{l}\text { Gezonde slaap en slaapproblemen bij } \\
\text { kinderen }\end{array}$ & $\begin{array}{l}\text { Voorkeurshouding en schedelvor- } \\
\text { ming }\end{array}$ & $\begin{array}{l}\text { Voorkeurshouding en schedelvor- } \\
\text { ming }\end{array}$ \\
\hline 5. & Taalontwikkeling & Overgewicht & Taalontwikkeling & Ondergewicht \\
\hline 6. & Niet scrotale testis (NST) & Voorkeurshouding en schedelvorming & Kindermishandeling & Taalontwikkeling \\
\hline 7. & Voorkeurshouding en schedelvorming & Taalontwikkeling & Borstvoeding & Kindermishandeling \\
\hline 8. & Huidafwijkingen & Preventie wiegendood & Opsporen oogafwijkingen & Extremiteiten \\
\hline 9. & Overgewicht & Borstvoeding & Pesten & Begeleiding gezin bij overlijden kind \\
\hline 10. & $\begin{array}{l}\text { Vroeg en/of small gestational age } \\
\text { (SGA) geboren kinderen }\end{array}$ & Excessief huilen & Voeding en eetgedrag & Heupdysplasie \\
\hline
\end{tabular}

2. De JGZ-richtlijn is specifiek voor de jeugdarts/ jeugdverpleegkundige (15 keer). Bijvoorbeeld: 'Heup-/hart-/gehoor-/oogonderzoek wordt door de jeugdarts gedaan. Indien ik vragen hierover heb, haal ik de jeugdarts erbij.'

3. Het bestaan van de richtlijn is onbekend (10 keer). Bijvoorbeeld: 'Van een aantal richtlijnen wist ik niet eens van het bestaan.'

\section{Beschouwing}

De vragenlijst is ingevuld door 183 JGZ-professionals. Het betrof jeugdartsen, verpleegkundig specialisten en jeugdverpleegkundigen en twee doktersassistentes. De peiling is dus vooral indicatief voor het gebruik van richtlijnen door jeugdartsen, verpleegkundig specialisten en jeugdverpleegkundigen.

Er zijn enkele kanttekeningen te maken bij de uitvoering van dit onderzoek. De deelnemende JGZ-professionals waren voornamelijk werkzaam in de zorg voor jeugdigen van 0 tot 4 jaar. Het is niet bekend of zij een representatief beeld geven van het gebruik van richtlijnen door de gehele groep JGZ-professionals 0 tot 18 jaar. Het is niet ondenkbaar dat vooral professionals die positief staan ten opzichte van richtlijnen de vragenlijst hebben ingevuld. Zo zouden het gebruik en de compleetheid van het gebruik te hoog ingeschat kunnen zijn. Ten slotte zijn de vragen die tijdens dit onderzoek werden gebruikt in eerder onderzoek gebruikt [4], maar zijn ze niet gevalideerd. Het is dus niet zeker of ze meten wat ze zouden moeten meten. De vragenlijst is uitgegaan van het gebruik van richtlijnen in casussen waarbij de richtlijn van toepassing is. Het blijkt dat dit niet door alle professionals zo is geïnterpreteerd. Daarnaast was het uitgangspunt dat JGZ-professionals een richtlijn als 'niet van toepassing' aanmerkten als deze niet relevant was voor hun doelgroep of discipline. Ook dit blijkt niet altijd het geval te zijn geweest. De gevonden resultaten moeten dus al met al als indicatief worden aangemerkt.

In het huidige onderzoek is het gebruik zoals bedoeld voor verbetering vatbaar. Zo kan bij de implementatie meer aandacht worden besteed aan de beschikbare tijd, kennis en vaardigheden [10]. Bij het ontwikkelen van de richtlijn dient aandacht te zijn voor het voordeel voor professionals en de compleetheid, sterkte en formulering van aanbevelingen. Wat mogelijk ook een rol speelt is dat er de afgelopen jaren een groot aantal nieuwe richtlijnen is gepubliceerd en geïmplementeerd. De komende jaren zal borging van bestaande JGZ-richtlijnen een aandachtspunt dienen te zijn.

Er zijn verschillen zichtbaar tussen het gebruik en het gebruik zoals bedoeld. Zo worden de richtlijnen Voorkeurshouding en schedelvorming en Lengtegroei door veel professionals (bijna) altijd gebruikt. Het gebruik zoals bedoeld is voor de richtlijn Voorkeurshouding en schedelvorming echter aanzienlijk beter dan voor de richtlijn Lengtegroei (89\% versus 58\%). De richtlijnen ADHD, Vroeg en/of small gestational age (SGA) geboren kinderen, Seksuele ontwikkeling en Angst worden niet alleen relatief weinig gebruikt, maar ook veelal niet gebruikt zoals bedoeld. Van andere richtlijnen, zoals de richtlijnen Ondergewicht, Voedselovergevoeligheid en Heupdysplasie, ligt het gerapporteerde gebruik lager, maar worden beide kernaanbevelingen meestal wel toegepast. Een verklaring hiervoor kan zijn dat de kennis uit de richtlijnen basiskennis is, of als basiskennis wordt gezien. Hierdoor kan het gebeuren dat een professional zich er niet van bewust is de richtlijn te gebruiken, maar toch volgens de richtlijn werkt.

Voor enkele JGZ-richtlijnen is opvallend vaak aangegeven dat deze 'niet van toepassing' zijn (data niet getoond). Sommige van deze richtlijnen bevatten aanbevelingen gericht op jeugdigen van 0 tot 18 jaar die relevant zijn voor zowel jeugdartsen als jeugdverpleegkundigen. Het is niet bekend waarom JGZ- 
professionals van mening zijn dat de richtlijn voor hen niet van toepassing is. Een mogelijke verklaring is dat men onvoldoende bekend is met het feit dat de richtlijn ook aanbevelingen bevat die voor 'hun' discipline of 'hun' doelgroep relevant is.

Tijdens een vergelijkbaar onderzoek in 2013 werd de richtlijn Opsporen oogafwijkingen (destijds Opsporing visuele stoornissen) net als in het huidige onderzoek het meest gebruikt zoals bedoeld [4]. Een andere overeenkomst met andere onderzoeken is dat de factor 'onvoldoende tijd' opvallend vaak als knelpunt wordt genoemd [4, 10, 11]. Dit gebrek aan tijd kan op twee manieren uitgelegd worden. Het kan zijn dat tijdens een consult te weinig tijd beschikbaar is om alle aanbevelingen uit de relevante JGZ-richtlijnen uit te voeren. Daarnaast geven JGZ-professionals aan dat ze soms onvoldoende tijd hebben om op de hoogte te blijven van alle richtlijnen. Een ander veelgenoemd knelpunt is onvoldoende kennis. Het op regelmatige basis organiseren van scholingen op lokaal en landelijk niveau blijft een aandachtspunt, zowel om nieuwe kennis te verspreiden, als om bestaande kennis te borgen.

Door toenemende flexibilisering en vraaggericht werken komen in de consulten niet meer alle onderwerpen op vaste leeftijden aan de orde. JGZprofessionals geven aan dat niet alle JGZ-richtlijnen hier voldoende rekening mee houden. Dit kan een deel van de gevonden verschillen in het gebruik van richtlijnen verklaren.

De bevinding dat JGZ-professionals vinden dat sommige richtlijnen niet tot hun taak behoren, kan te maken hebben met de leeftijdsgroep waar ze mee werken of de discipline van de JGZ-professional. Zo werd deze reden bijvoorbeeld vaak genoemd bij de richtlijn Niet-scrotale testis, die vooral relevant is voor jeugdartsen die werkzaam zijn in de zorg voor jeugdigen van 0 tot 4 jaar. Het signaal dat richtlijnen niet aansluiten bij de bestaande werkwijze kan te maken hebben met het feit dat veel JGZ-richtlijnen relatief oud zijn. Ten tijde van het onderzoek waren 17/35 JGZ-richtlijnen ouder dan vijf jaar.

De meest genoemde belemmerende factor is een tekort aan tijd. Daarnaast bieden enkele richtlijnen de professional te weinig voordeel, of sluiten deze volgens JGZ-professionals maar matig aan bij de praktijk. Richtlijnontwikkelaars spelen hierin een belangrijke rol door aandacht te schenken aan de aansluiting van de richtlijnen bij de praktijk van de professionals. Ook individuele professionals en organisaties kunnen hieraan bijdragen, bijvoorbeeld door deelname aan landelijke commentaarrondes en proefimplementaties.

Eerdere onderzoeken naar het gebruik van richtlijnen in andere settingen lieten vergelijkbare resultaten zien [10-12]. In een onderzoek onder Nederlandse huisartsen bleek de toepassing van diverse aanbevelingen uit standaarden van het Nederlands Huisartsen Genootschap (NHG) te variëren van $52 \%$ tot $95 \%$ [13].
Richtlijnen dragen bij aan een vermindering van de variatie in handelen, en bevorderen het evidencebased handelen van professionals [3]. De effectiviteit van een richtlijn is afhankelijk van zowel de werkzaamheid (efficacy), als de mate van gebruik zoals bedoeld (implementatie). De werkzaamheid van een richtlijn valt buiten het kader van dit artikel. Maar wanneer een richtlijn werkzaam is, maar niet of slechts gedeeltelijk wordt uitgevoerd, zullen de beoogde effecten bij jeugdigen (de eindgebruikers) voor een belangrijk deel achterwege blijven [1].

Concluderend is er een grote variatie in het gebruik van richtlijnen, net als in het gebruik zoals bedoeld. Voor het merendeel van de onderzochte richtlijnen is verbetering mogelijk. Het regelmatig onderzoeken van het gebruik van richtlijnen biedt goede aanknopingspunten voor de implementatie van specifieke richtlijnen en de prioritering van bijvoorbeeld updates van richtlijnen. Tevens is het op zijn plaats om een vinger aan de pols te houden op momenten dat er belangrijke veranderingen plaatsvinden in de JGZpraktijk (zoals de toenemende flexibilisering) en/of richtlijnontwikkeling (bijvoorbeeld de nieuwe, modulaire opzet). Dit onderzoek kan worden beschouwd als nulmeting voor de invoering van de modulaire werkwijze van JGZ-richtlijnen.

\section{Literatuur}

1. Glasziou P, Straus S, Brownlee S, Trevena L, Dans L, GuyattG, et al. Evidence for underuse of effective medical services around the world. Lancet. 2017;390(10090):169-77.

2. Prior M, Guerin M, Grimmer-Somers K. The effectiveness of clinical guideline implementation strategies-a synthesis of systematic review findings. J Eval Clin Pract. 2008;14(5):888-97.

3. Grimshaw J, Freemantle N, Wallace S, Russell I, Hurwitz B, Watt I, et al. Developing and implementing clinical practice guidelines. Qual Health Care. 1995;4(1):55-64.

4. Lanting CI, Fleuren M, Broekhuizen K. Kennisname en gerapporteerd gebruik van de JGZ richtlijnen gepubliceerd vóór 2012. TNO/CH2013 R10513. Leiden: TNO; 2013.

5. Van Zoonen R, Deurloo JA, Lanting C. Wat leren we van de praktijktests van JGZ-richtlijnen? JGZ Tijdschr Jeugdgezondheidsz. 2021;53:126-9.

6. Langendam M. Modulaire vormgeving richtlijnen Jeugdgezondheidszorg. Amsterdam: AMC/Universiteit van Amsterdam, Amsterdam Public Health Research Institute; 2021.

7. Heinen M, Staal B, Bakker-Jacobs A. Herziening, versnelling en vernieuwing richtlijnen JGZ 2016-2021. Nijmegen: IQ Healthcare; 2017.

8. Dijk K, Cornelisse A, La Haye D. Richtlijnen Jeugdgezondheidszorg. Slimmer \& Sneller. Leeuwarden: GGD Fryslân; 2019.

9. Fleuren MAH, Paulussen TGWM, Van Dommelen P, Van Buuren S. Towards a measurement instrument for determinants of innovations. Int J Qual Health Care. 2014;26(5):501-10.

10. Correa VC, Lugo-Agudelo LH, Aguirre-Acevedo DC, Contreras JAP, Borrero AMP, Patiño-Lugo DF, et al. Individual, health system, and contextual barriers and facilitators for 


\section{Onderzoeksartikel}

the implementation of clinical practice guidelines: a systematic metareview. Health Res Policy Sys. 2020;18(1):74.

11. McArthur C, Bai Y, Hewston P, Giangregorio L, Straus S, Papaioannou A. Barriers and facilitators to implementing evidence-based guidelines in long-term care: a qualitative evidence synthesis. Implement Sci. 2021;16(1):1-25.

12. Sheldon TA, Cullum N, Dawson D, et al. What's the evidence that NICE guidance has been implemented? Results from a national evaluation using time series analysis, audit of patients' notes, and interviews. BMJ. 2004;329(7473):999.

13. Lugtenberg M, Burgers JS, Besters CF, Han D, Westert GP. Perceived barriers to guideline adherence: a survey among general practitioners. BMCFam Pract. 2011;12(1):1-9.
Dr. Jacqueline A. Deurloo, arts maatschappij en gezondheid, onderzoeker

Renate van Zoonen, onderzoeker

Aniek A.E.M. van den Braak, adviseur

Dr. Caren I. Lanting, epidemioloog, richtlijnontwikkelaar, artsn.p. 